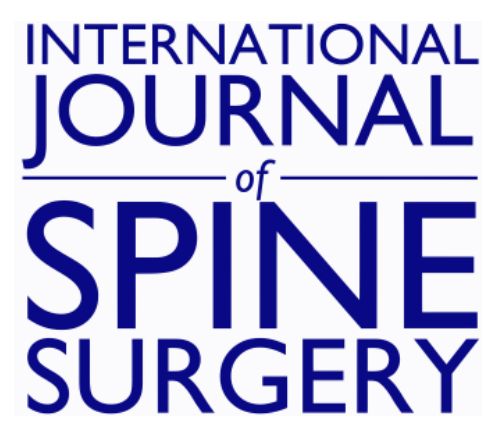

\title{
Measurement of Paradoxical and Coupled Motions Following Lumbar Total Disc Replacement
}

Soo-An Park, Nathaniel Ordway, Amir Fayyazi, Bruce Fredrickson and Hansen A. Yuan

Int J Spine Surg 2008, 2 (3) 137-139

doi: https://doi.org/10.1016/SASJ-2008-0005-RR

http://ijssurgery.com/content/2/3/137

This information is current as of April 26, 2023.

Email Alerts Receive free email-alerts when new articles cite this article. Sign up at:

http://ijssurgery.com/alerts

The International Journal of Spine Surgery

2397 Waterbury Circle, Suite 1,

Aurora, IL 60504, Phone: +1-630-375-1432

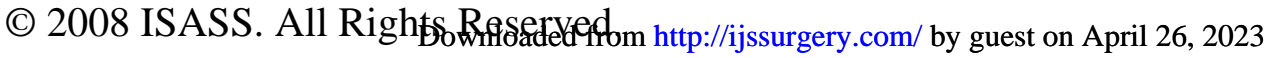




\title{
Measurement of Paradoxical and Coupled Motions Following Lumbar Total Disc Replacement
}

\author{
Soo-An Park, MD, PhD, ${ }^{a}$ Nathaniel Ordway, MS, PE, ${ }^{b}$ Amir Fayyazi, MD, ${ }^{c}$ Bruce Fredrickson, MD, ${ }^{b}$ \\ and Hansen A. Yuan, MD
}

\begin{abstract}
Background

Maintenance of segmental motion following lumbar total disc replacement (LTDR) is one of the theoretical advantages of spinal arthroplasty. This in vivo study examined paradoxical and coupled motions during sagittal plane movements following disc arthroplasty and compared these motions with those measured following lumbar discectomy.
\end{abstract}

\section{Methods}

Ten patients following LTDR using ProDisc-L (Synthes, Inc., West Chester, Pennsylvania) and 8 patients following lumbar discectomy (LD) were enrolled. At 1-month, 1-year and 2-year postoperative time-points, patients performed flexion/extension starting from a neutral position, and the intervertebral rotations were determined with radiostereometric analysis. The amount of intended and coupled motion was compared in each group and at each postoperative time. The frequency of paradoxical motion was compared between the 2 groups, and the effects of intended motion, operative-level, number of levels, and postoperative time-point were examined.

\section{Results}

The intended and coupled motions following LTDR and LD did not change over time and did not differ from each other for the flexion and total sagittal movements. The sagittal range of motion (ROM) of LTDR was significantly smaller than that of LD in extension $\left(-0.6^{\circ} \pm 1.1^{\circ}\right.$ vs $\left.-2.2^{\circ} \pm 1.6^{\circ}\right)$. LTDR exhibited a significantly higher rate of paradoxical motion when compared to LD (26.4\% vs $\left.6.7 \%\right)$. In LTDR, the rate of paradoxical motion at 1 month $(40 \%)$ was significantly higher than at 1 -year $(21.1 \%)$ or at 2 -year $(25.0 \%)$. The presence of paradoxical motion was significantly less frequent at L4-5 (19.2\%) when compared to L5-S1 (31.3\%) or L2-3 (36.4\%).

\section{Conclusion}

The overall sagittal ROM of LTDR was $3.5^{\circ} \pm 2.4^{\circ}$ and not significantly different than LD. The current study did not demonstrate a difference in coupled motions between LTDR and LD. The rate of paradoxical motion was significantly higher in LTDR than in LD. In LTDR, there was a significantly lower rate of paradoxical motion seen at L4-5 and significantly higher rate seen in the earlier postoperative period.

\section{Level of Evidence \\ Prospective cohort study with good follow-up (level 1b).}

Key Words: Lumbar total disc replacement, disc arthroplasty, discectomy, paradoxical motion, coupled motion. SAS Journal. Summer 2008;2:137-139. DOI: SASJ-2008-0005-RR

${ }^{a}$ Asan Medical Center, Orthopedic Surgery, Seoul, Korea; bSUNY Upstate Medical University, Syracuse, New York; ' VSAS Orthopaedics, Allentown, Pennsylvania

Address correspondence to Dr. Soo-An Park, Orthopedic Surgery, Asan Medical Center, Poong-Nap 2 dong 388-1, Seoul, 138-736, Republic of Korea, email: sooan.park@gmail.com

The authors have no financial interest or other potential conflicts of interest to report in relation to the device used in this study.

Acknowledgment: Partial research support was received from Synthes, Inc. (West Chester, Pennsylvania) and DePuy Spine, Inc. (Raynham, Massachusetts.).

Approval for this study was obtained from the Institutional Review Board of SUNY Upstate Medical University, Syracuse, New York

\section{INTRODUCTION}

Maintenance of segmental motion following lumbar total disc replacement (LTDR) is one of the theoretical advantages of spinal arthroplasty when compared to spinal fusion for the treatment of lumbar degenerative disc disease. The presence of motion following LTDR decreases the amount of stress and strain on the adjacent level and can potentially decrease the rate of adjacent segment disease. Theoretically, the amount of motion is important in preventing adjacent segment disease, and at the same time abnormal motion can result in early facet degeneration. ${ }^{1}$
The kinematics of a spinal segment are quite complex. In addition to the intended motion, paradoxical and coupled motions do occur and can have adverse effects on the facet joints. ${ }^{2}$ Paradoxical motion is defined as a motion opposite of intended motion, whereas coupled motions are defined as combined motions in planes perpendicular to the intended motion. To our knowledge, 3-dimensional motions with paradoxical and coupled motions have not been well studied following LTDR. Radiostereometric analysis (RSA) is an in vivo technique that can precisely measure 3-dimensional spinal motion with high accuracy and therefore has the 
potential to measure both paradoxical and coupled motions. ${ }^{3}$ This study was designed to precisely measure the amount and quality of motion following LTDR in 3 dimensions (intended and coupled motions) and compare post-LTDR motion to motion seen following lumbar discectomy (LD).

\section{MATERIALS AND METHODS}

The Institutional Review Board approved this study, and all subjects received informed consent documentation. Ten patients (6 males and 4 females, $47 \pm 7$ years) with lumbar disc degeneration at L2-3, L4-5, and/or L5-S1 were enrolled to undergo disc arthroplasty (LTDR group) with ProDisc-L (Synthes Spine, Inc., West Chester, Pennsylvania). Eight patients (4 males and 4 females, $41 \pm 6$ years) with lumbar disc herniation at either L4-5 or L5-S1 were enrolled to undergo lumbar discectomy (LD group). The patients were followed postoperatively at 1 month, 1 year and 2 years. Fourteen levels following LTDR and 8 levels following LD were analyzed for this study. Standard surgical techniques were followed, and the procedures were performed by 3 spine surgeons. During the operation, $3-5$ tantalum beads ( 0.8 or $1.0 \mathrm{~mm}$ diameter) were implanted into each vertebra. At each postoperative follow-up, biplanar standing-neutral (ST), forward bending (FB), and backward bending (BB) radiographs were obtained, and 3-D segmental motions were measured using RSA. ${ }^{4}$

Intended (sagittal rotation: sRot) and coupled motions (axial rotation: aRot; coronal rotation: cRot) were calculated for flexion (ST to FB), extension (ST to BB), and total sagittal (BB to FB) movements. The paradoxical motion was determined as either positive or negative for each flexion and extension movement.

\section{Statistical Methods}

To evaluate the presence and the change of the coupled motions in addition to the intended motion over time, 3 dependent variables (sRot, aRot, and cRot) were tested with a $2 \times 3$ (operation $\times$ time) MANOVA. In order to evaluate the frequency of the paradoxical motion, a nonparametric binomial test was performed for the frequency of paradoxical rotation against flexion and extension with comparing LTDR to LD. To analyze additional factors that may affect the frequency of paradoxical motion within LTDR, binomial tests were performed with comparing the movements (flexion to extension), the levels (L4-5 to L2-3 and L5-S1), the time-point (1 month to 1 year and 2 years) and the number of implanted levels (mono-segmental and bi-segmental).

\section{RESULTS}

The motions (intended and coupled) following LTDR and LD did not change over time. Motions of flexion post-LTDR compared to post-LD and total sagittal range of motion in the 2 groups were not significantly different (Table 1 ). However, sRot following LTDR was significantly smaller than that following $\mathrm{LD}$ in extension $\left(-0.6^{\circ} \pm 1.1^{\circ}\right.$ vs $-2.2^{\circ} \pm 1.6^{\circ}, P=$ $.004)$.
Table 1. Average Range of Motion Over Time for Lumbar Total Disc Replacement and Lumbar Discectomy

\begin{tabular}{lllll}
\hline Procedure & Movement & sRot & $\begin{array}{l}\text { Rotation } \\
\text { cRot }\end{array}$ & aRot \\
\hline LTDR & Flexion & $1.8 \pm 3.3$ & $-0.4 \pm 0.8$ & $0.2 \pm 0.9$ \\
& Extension & $-0.6 \pm 1.1$ & $-0.2 \pm 0.7$ & $-0.1 \pm 0.8$ \\
& Total Sagittal & $3.5 \pm 2.4$ & $0.8 \pm 0.7$ & $1.0 \pm 0.7$ \\
\hline LD & Flexion & $2.8 \pm 2.6$ & $0.0 \pm 0.2$ & $-0.2 \pm 1.0$ \\
& Extension & $-2.2 \pm 1.6$ & $0.1 \pm 0.9$ & $0.0 \pm 0.3$ \\
& Total Sagittal & $4.7 \pm 2.2$ & $0.7 \pm 1.4$ & $1.5 \pm 2.6$ \\
\hline
\end{tabular}

LTDR patients exhibited a significantly higher rate of paradoxical motion when compared to LD patients $(26.4 \%$ vs $6.7 \%, P<.001)$. In the LTDR group, rate of paradoxical motion was $40 \%$ at 1 month and was significantly higher than the $21.1 \%$ measured at 1 year $(P=.001)$ and the $25 \%$ measured at 2 years $(P=.001)$. The presence of paradoxical motion was significantly less frequent at L4-5 $(19.2 \%)$ than at L5-S1 $(31.3 \%, P<.001)$ or at L2-3 $(36.4 \%, P=.001)$. There was no significant difference in the presence of paradoxical motion based on the number of levels implanted (Table 2). In addition, coupled motions were not significantly present in either the LTDR or the LD group.

Table 2. Nonparametric Binomial Tests for the Proportion of Paradoxical Motions in LTDR

\begin{tabular}{|c|c|c|c|c|}
\hline LTDR & $\mathrm{N}$ & $\begin{array}{l}\text { Proportion of } \\
\text { Paradoxical } \\
\text { Motion } \\
\text { Mean (SD) }\end{array}$ & Test w/ & Test Proportion \\
\hline Total & 53 & $0.264(0.445)^{*}$ & LD Total & 0.067 \\
\hline Flexion & 26 & $0.269(0.452)$ & $\begin{array}{l}\text { LTDR Exten- } \\
\text { sion }\end{array}$ & 0.259 \\
\hline Extension & 27 & $0.259(0.447)$ & & \\
\hline L4-5 & 26 & $0.192(0.402)$ & & \\
\hline $\mathrm{L} 2-3$ & 11 & $0.364(0.505)^{*}$ & LTDR L4-5 & 0.192 \\
\hline L5-S1 & 16 & $0.313(0.479)^{*}$ & LTDR L4-5 & 0.192 \\
\hline $1 \mathrm{Mo}$ & 10 & $0.400(0.516)$ & & \\
\hline $1 Y r$ & 19 & $0.211(0.419)^{*}$ & LTDR 1 Mo & 0.4 \\
\hline $2 Y r$ & 24 & $0.250(0.442)^{*}$ & LTDR $1 \mathrm{Mo}$ & 0.4 \\
\hline
\end{tabular}

Mono-segmental 340.265 (0.448)

$\begin{array}{lllll}\text { Bi-segmental } & 19 & 0.263(0.452) & \text { LTDR 1-level } & 0.265\end{array}$

Comparison of total cases between LTDR and LD and comparison of LTDR cases between each motion, level, post-operative time-point and number-of-operation.

*Significantly different with changes in testing proportion

\section{DISCUSSION}

The presence and the quantity of segmental motion following LTDR have not yet been demonstrated to correlate with better clinical outcomes or to prevent adjacent segment degeneration. The overall sagittal ROM following LTDR in the current study, regardless of the level and time, was $3.5^{\circ}$ $\pm 2.4^{\circ}$ and not significantly different than the amount of 
motion measured following LD. However, the magnitude of extension was significantly smaller in the LTDR during the sagittal motions. Although the sagittal ROM was smaller in comparison to Delamarter et al.,$^{5}$ it is important to note that the 1-month time-point displayed the lowest ROM $\left(2.5^{\circ} \pm\right.$ $\left.2.7^{\circ}\right)$ compared to the later time-points $\left(3.9^{\circ} \pm 4.7^{\circ}\right.$ and $5.1^{\circ} \pm$ $3.6^{\circ}$, respectively). The lower ROM and the higher incidence of paradoxical motion at the 1-month time-point are likely due to the recovery process following surgery.

Segmental motion following LTDR has been shown by others to be affected by surgical technique. McAfee et al. ${ }^{6}$ demonstrated that LTDR patients with implants positioned more than $5 \mathrm{~mm}$ from the ideal location showed a smaller amount of motion. Proper placement of the implant in each axis should be the prerequisite of better clinical outcome and adequate segmental motion following LTDR. Malpositioned cases in the coronal and sagittal axes have not been included in the current study to decrease the confounding effects of surgical technique.

There was a significant difference in the quality of motion following LTDR compared to the LD group. The rate of paradoxical motion was significantly higher in LTDR compared to post-LD measurements. There were significant differences noted between the operative levels, with a significantly lower rate of paradoxical motion seen at L4-5, and between the follow-up times, with a significantly higher rate seen in the earlier postoperative period following LTDR.

The current study did not demonstrate the presence of coupled motions following LTDR or LD during sagittal motion. This result was expected since coupled motions occur with the intended motion of either lateral bending or axial rotation in the lumbar spine. Further kinematic study of both paradoxical and coupled motions will be necessary to understand the clinical effects, if any, from disc arthroplasty on the posterior structures as well as the adjacent levels.

This manuscript was submitted April 3, 2008, and accepted for publication June 5, 2008.

\section{REFERENCES}

1. Le Huec JC, Basso Y, Aunoble S, et al. Influence of facet and posterior muscle degeneration on clinical results of lumbar total disc replacement: two-year follow-up. J Spinal Disord Tech. 2005;18:219-223.

2. White AA, Panjabi MM. Clinical Biomechanics of the Spine. 2nd ed. Philadelphia, PA: Lippincott Williams \& Wilkins; 1990.

3. Leivseth G, Kolstad F, Nygaard OP, et al. Comparing precision of distortion-compensated and stereophotogrammetric Roentgen analysis when monitoring fusion in the cervical spine. Eur Spine J. 2006;15:774779 .

4. Ordway NR, Fayyazi AH, Abjornson C, et al. Twelve-month follow-up of lumbar spine range of motion following intervertebral disc replacement using radiostereometric analysis. SAS Journal. 2008;2:9-15.

5. Delamarter RB, Fribourg DM, Kanim LE, et al. ProDisc artificial total lumbar disc replacement: introduction and early results from the United States clinical trial. Spine. 2003;28:S167-175.
6. McAfee PC, Cunningham B, Holsapple G, et al. A prospective, randomized, multicenter Food and Drug Administration investigational device exemption study of lumbar total disc replacement with the CHARITE artificial disc versus lumbar fusion: part II: evaluation of radiographic outcomes and correlation of surgical technique accuracy with clinical outcomes. Spine. 2005;30:1576-83; discussion E388-90. 